\title{
Modelos y prácticas educativas en sociedades multiculturales complejas
}

\author{
Dr. Eligio Cruz Leandro \\ Académico del Instituto de Investigaciones Antropológicasde la \\ Universidad Nacional Autónoma de México \\ eligiocruz@live.com.mx
}

Recepción:28/05/2021

Aceptación:21/06/2021

\section{Resumen}

El problema de la educación, es un problema complejo que es producto de circunstancias históricas y modelos de desarrollo que se han impuesto de los países desarrollados. En México con los modelos implantados el siglo pasado, el de sustitución de importaciones y el neoliberal. En ambos casos, se produjeron grupos sociales marginados y multiculturales, a los que se ha pretendido en las últimas décadas imponer un modelo educativo. Sin embargo, tanto los grupos urbanos como las comunidades han presentado resistencia, debido a que las reglas de convivencia y su devenir social y cultural de colaboración y bienestar común, chocan con la lógica del sistema capitalista, que es de individualista y mercantil. Aun con las agresiones que han sufrido por parte de las autoridades, de manera local educan conforme a su contexto, posibilidades y aspiraciones sociales.

\section{Palabras clave}

Educación, marginación, multiculturalismo, complejidad

\section{Abstract}

The problem of education is a complex problem that is the product of historical circumstances and development models that have been imposed from developed countries. In Mexico with the models implemented in the last century, the import substitution and the neoliberal. In both cases, marginalized and multicultural social groups were produced, to which it has been tried in the last decades to impose an educational model. However, both urban groups and communities have resisted, because the rules of coexistence and their social and cultural evolution of collaboration and common welfare, collide with the logic of the capitalist system, which is individualistic and commercial. Even with the attacks they have suffered by the authorities, they educate locally according to their context, possibilities and social aspirations.

\section{Keywords}

Education, marginalization, multiculturalism, complexity. 


\section{Antecedentes}

Desde hace muchos años se ha afirmado, de manera categórica, que la educación en México es mala, por múltiples razones, pero sobre todo porque las evaluaciones de los organismos internacionales así lo afirman.

Sin duda, siempre existen posibilidades de ser mejores y hacer más en cualquier ámbito de la vida; también es cierto que, en los sistemas educativos, especialmente en los de los países pobres, existen muchas necesidades, actualización de los profesores, mejores sueldos, infraestructura física y tecnológica. Además, también es cierto que los estudiantes tienen muchas necesidades, vivienda, alimentación, servicios de salud y muchas insuficiencias básicas insatisfechas.

El problema de la educación, es un problema complejo y no depende de pocas variables en las que se pueda intervenir de manera sencilla en un entorno complejo como en el que vivimos los países de América Latina.

Tampoco, podemos afirmar terminantemente que la educación que se imparte en los países desarrollados sea buena, por el hecho de que los estudiantes, profesores y autoridades cuentan con mayores recursos.

En todo caso, en principio es conveniente dilucidar, en principio ¿Cómo definimos la educación? Y si la educación es mala, también debemos preguntarnos, desde un esquema de pensamiento contextual o situado, ¿para quién es mala? Y si es buena, ¿Para quién es buena?

Para contestar esas preguntas de manera pertinente, el objetivo del presente artículo será el de revisar y conocer el devenir histórico de la historia intermedia, en este caso de México; revisar cómo los acontecimientos económicos políticos y sociales han afectado el ámbito educativo.

\section{Las disciplinas, la linealidad y la norma- lidad en las ciencias.}

En la historia del pensamiento, la concepción clásica de la ciencia establece que para que sea válido el conocimiento, se deben poner en orden los fenómenos, rechazar el desorden y la incertidumbre, distinguir y jerarquizar. En El Discurso del Método, René Descartes (1637), postuló como principio de verdad las ideas claras y distintas, indicó que todo conocimiento opera mediante la selección de datos significativos, distinguiendo, uniendo, centralizando y jerarquizando. Indicó que que para llegar al conocimiento es necesario dividir (reducir) los problemas en tantas partes como se pu- diera para resolverlos mejor.

Por otra parte, Newton (1687) considera la realidad como una gran máquina, regida por leyes deterministas, inspirado en el principio de causa-efecto indicó que el mundo se puede explicar y pronosticar como un sistema mecánico.

La filosofía de Descartes y la física mecanicista de Newton, han prestado grandes servicios al desarrollo de las ciencias, no solo de aquellas a las que se les denomina "exactas", sino también en las ciencias sociales, a las que peyorativamente se les califica como "blandas". La linealidad, causalidad, reduccionismo y mecanicismo, continúan presentes no solo en la ciencia, sino en otros campos del conocimiento como el de la organización social y el desarrollo del sistema capitalista.

En las ciencias sociales existen una gran cantidad de modelos simples construidos bajo esa percepción, por ejemplo, en la Teoría Económica tenemos los modelos micro y macroeconómicos y en las ciencias administrativas los modelos para organizar la producción de bienes y servicios.

La Escuela de Administración Científica de Frederick Taylor (1856-1915) y la Teoría Clásica de Henri Fayol 1841-1925), constituyen las bases del llamado enfoque clásico tradicional de la administración que utilizaron y continuan usando modelos lineales y disciplinares para identificar, analizar, controlar, pronosticar y buscar equilibrio en organizaciones.

- División del trabajo.

- Unidad de mando.

- Procesos

- Líneas de producción

- Disciplina, subordinación

- Tiempos y movimientos

A fines del siglo XIX y principios del XX, la productividad era en estrategia fundamental para cualquier empresa, puesto que no solo le permitía elevar sus ingresos, sino le aseguraba el crecimiento y la posición de mercado. La producción industrial buscaba obtener utilidades con la organización de operaciones secuenciales (producción en línea), para la fabricación de un gran número de productos estandarizados. Esta estrategia, implica la organización del proceso productivo en fases, para transformar materia prima en productos terminados. Asimismo, la especialización de las máquinas y de los trabajadores repercute en un menor tiempo de producción y una mayor productividad. 


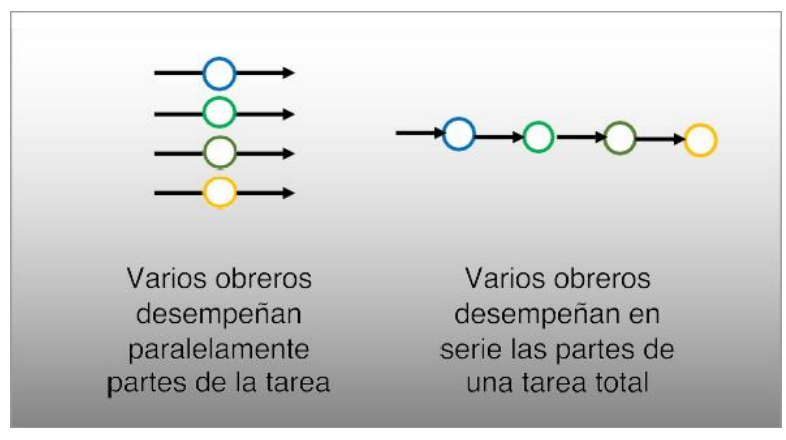

Figura 1. Producción en Línea. Elaboración propia.

Aunque las formas de organización para producir bienes o servicios han cambiado, la educación continua organizándose como lo hacía en la sociedad industrial. La educación está diseñada por pedagogos de los siglos XIX y XX y responden al ideal de una fábrica que produce en serie.

De la misma manera en que se producen bienes y servicios en una fábrica, la educación se ha concebido también como un proceso lineal, en el que el aula es una línea de montaje con la que se pueden formar "modelos de ciudadanos" que responden a una preconcepción de lo que se considera "buenos ciudadanos". Esto es, personas normalizadas que responden a un estereotipo que tiene las siguientes cualidades:

- Se somete a las leyes y reglas del sistema

- Mantiene su entorno limpio

- Reduce la cantidad de basura

- Administra el agua

- Utiliza la bicicleta

- Está al tanto de lo que sucede en su ciudad

- Participa activamente

- Conoce a sus vecinos y se relaciona con ellos

- Fomenta la paz y el respeto

- Consume del comercio local

- Visita sus espacios públicos y los cuida.

Para transformar niños "normales" o normalizados en modelos de ciudadanos, las escuelas se han constituido en fábricas o unidades de producción, con las que se pretende transformar a los estudiantes mediante procesos lineales y disciplinares.

Esto es una infraestructura física que cuenta con personal especializado en distintas materias, un currículo oficial que corresponde a un plan de estudios diseñado por fases, en donde en cada una de ellas se les dota de conocimientos o competencias, conforme a un perfil de egreso, que al final de cada proceso es evaluado, para constatar que cumple con los atributos de un producto final, que atiende la demanda de un mercado, esto es el mercado laboral.

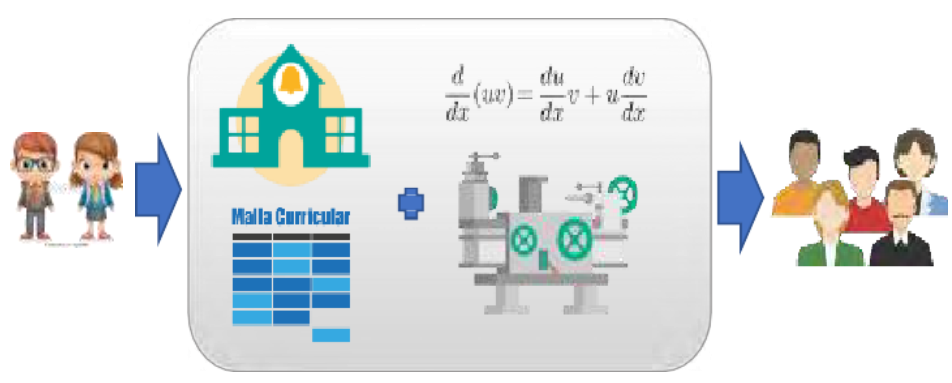

Figura 2. Sistema educativo conservador. Elaboración propia.

Estos procesos se llevan a cabo bajo una concepción conservadora de la educación, en la que es deseable que la sociedad "exista y se conserve"; para ello es fundamental que el resultado del proceso educativo sean individuos cuyo comportamiento se evalúe como correcto.

Esta manera de educar, estaba dirigida a una persona media, normal o estándar, para producir modelos de ciudadanos normales o estándar, buenos ciudadanos. Que conserven el modelo de sociedad que les dio origen.

Dicha noción de la educación, responde a la concepción de la física social de Adolphe Quetelet (1796-1874), quien negaba el papel del azar y afirmaba que los fenómenos sociales atienden a ciertas causas, y que las regularidades se pueden identificar por medio de física estadística, a través de la cual es posible observar reglas que subyacen en el orden social.

Quetelet propuso el concepto de "hombre medio" (I'homme moyen), cuyas dimensiones y rasgos físicos, amén de sus atributos morales y estéticos, representaban a un hombre perfecto, que se ajusta al promedio: "un individuo que, en un momento dado, es el epítome de todas las cualidades del hombre promedio, representaría toda la grandeza, belleza y bondad del ser" (Quetelet, 1848).

También, manifestó poder observar las desviaciones de las conductas sociales con un determinismo absoluto al afirmar que "Podemos enumerar anticipadamente cuántos individuos mancharán sus manos con la sangre de sus semejantes, cuántos serán falsificadores, cuántos envenenadores, con tanta precisión como podemos enumerar la cantidad de nacimientos y muertes que ocurrirán en una sociedad" (Quetelet, 1848).

Esta visión de normalidad idealizada, aborrece de todas las irregularidades que se presentan en el aula, distingue y discrimina a los estudiantes y profesores que 
no responden al modelo establecido socialmente. Por tanto, la función conservadora, lineal, disciplinar y normalizadora de la educación tiene como objetivos:

- Formar individuos conforme a la colectividad

- Evitar desviaciones dañinas al sistema

- Transmitir la cultura

- Reproducir el orden social

- Mantener el status quo o condiciones que prevalecen en la sociedad

Por tanto, la estandarización de los procesos educativos está orientada a determinar lo que el profesor va a enseñar y los contenidos establecen lo que debe aprender el estudiante, las destrezas y conocimientos que debe adquirir en función de una necesidad social, económica y política.

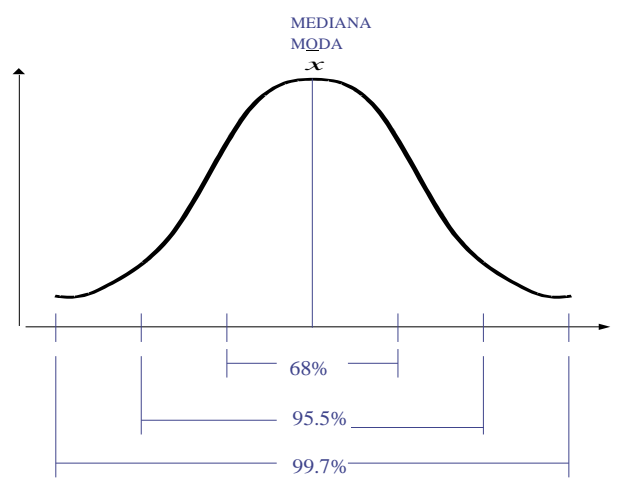

Figura 3. Curva normal. Elaboración propia.

Esto es, formar personas, que conforme a las áreas de la curva normal, se ubiquen dentro de la mediana, la moda y se alejen lo más posible de la zona de las irregularidades. El grupo conservador que impone el aprendizaje, no sólo busca conformar individuos socialmente aceptables y útiles, sino también evitar brotes de desviaciones dañinas.

\section{La educación en México}

En México se siguieron al pie de la letra las directrices establecidas por la Organización para la Cooperación y el Desarrollo Económicos (OCDE). En 2008 se firmó un convenio de colaboración para "El mejoramiento de la educación escolar en las escuelas mexicanas", enfocado a "la innovación y a una efectiva política de reformas" que consideró cinco áreas principales: 1 . Administración escolar y participación social; 2. Selección y reclutamiento de maestros; 3. Formación docente y capacitación; 4. Incentivos y estímulos para los maestros y 5 . Evaluación docente.

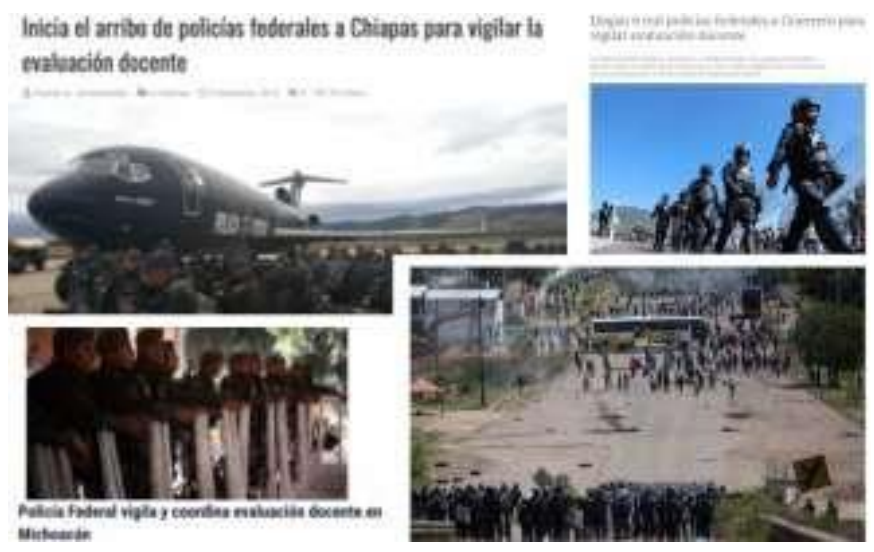

Figura 4. Medidas para imponer la reforma educativa. Elaboraciónpropia, con imágenes de los diarios

Sin embargo, en los hechos dicha reforma se redujo a la evaluación de los profesores y estuvo enfocada a desarticular a los grupos opositores que se concentraban, sobre todo en los estados más pobres del país, como Chiapas, Michoacán, Guerrero y Oaxaca, quienes fueron reprimidos y denostados por el gobierno, empresarios y medios de comunicación, a lo largo de una década.

El hecho es que utilizaron a la Policía Federal y a las policías estatales para aplicar una evaluación a los profesores, con la que se "constataría" que cuentan con las aptitudes y "competencias" para impartir educación en sus respectivas comunidades.

\section{Periodo de sustitución de importaciones y migración}

Para entender la situación educativa en México, es necesario revisar, por lo menos, como han influido los modelos de desarrollo económico, desde la posguerra hasta nuestros días.

El modelo económico de Sustitución de Importaciones fue aplicado por la mayoría de los países de América Latina, como estrategia de los países industrializados, principalmente Estados Unidos e Inglaterra, para enfrentar la Gran Depresión de 1929 y la reconstrucción por los daños derivados de la Segunda Guerra Mundial.

Se impulsó este modelo de industrialización, de acuerdo con el paradigma de Keynes, para lo cual era necesario promover un Estado fuerte y proteccionista en América Latina, que garantizara la inversión, el empleo y la reactivación económica mediante el gasto público y su propuesta teórica del multiplicador de la inversión.

"... mientras el multiplicador es más grande en una comunidad pobre, el efecto de la fluctuación de la inversión sobre la ocupación será mucho mayor que 
en una comunidad rica, suponiendo que en ésta la inversión corriente representa una proporción mucho más grande de la producción corriente" (Keynes, 1936: 1943)

La industrialización por sustitución de importaciones prevaleció en México, aproximadamente, de los años 1940 a 1970, entre las medidas que se tomaron se incluyeron la aplicación de aranceles a la importación, tipos elevados de cambio, subsidios y apoyos para los productores locales. Una serie de medidas orientadas a desarrollar la industria nacional, ser productores y consumidores de bienes nacionales, básicamente en las ramas productivas de bienes de consumo y de bienes intermedios

Con el Modelo de Sustitución de Importaciones en México, la política económica se basó principalmente en:

- Protección de las empresas de competencia internacional

- Tipo de cambio sobrevaluado

- Incentivos a los productores, exenciones fiscales y subsidios

- Generación de empleo

- Gasto público hacia actividades que consideraba prioritarias.

Entre 1933 y 1982, la economía mexicana creció a una tasa anual promedio superior a $6 \%$ anual. Durante este mismo período se desarrolló la estructura productiva el país, los sectores, las ramas productivas y una gran cantidad de actividades vinculadas a la transformación industrial.

Para mostrar el resultado de este modelo económico, con el programa para diseñar redes neuronales Walrus y con información de la Secretaría de Economía, se cartografió la estructura productiva de México de las empresas que están formalmente vinculadas, como grandes, micro o pequeñas empresas, con el resultado que se muestra a continuación:
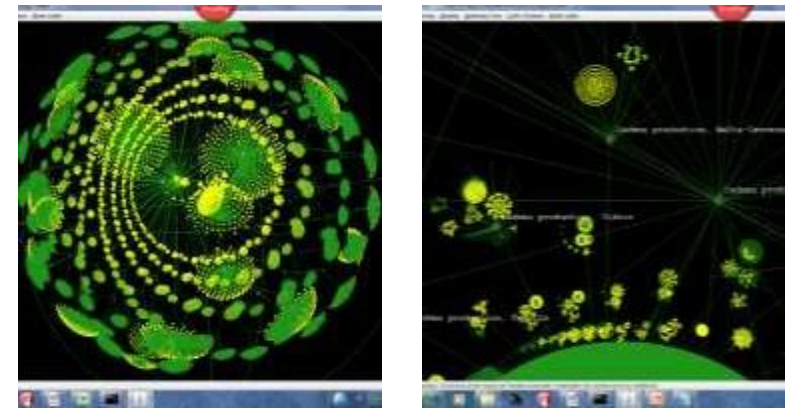

Figura 5. Red compleja de la estructura productiva de México. (Cruz,2011).
Entre los años 40 y 70 del siglo pasado, México pasó de ser predominantemente rural, a convertirse en un país mayoritariamente urbano, productor de bienes de consumo y bienes intermedios, con un mercado local relativamente fuerte, que gozó de la protección del Estado durante muchos años.

En los años 40, con el impulso al campo se crearon obras de infraestructura para obtener una mayor producción de cultivos de exportación, pero el apoyo fue principalmente para empresas privadas.

Los campesinos en su mayoría producían para su autoconsumo y al crecer las familias, muchos de sus integrantes tuvieron que emigrar a las grandes ciudades en busca de oportunidades ante el desarrollo industrial y la conformación del mercado interno, propiciando el crecimiento de los centros urbanos, pero sobre todos de las zonas periféricas.

La carencia de habitaciones fue el primer problema que enfrentaron los inmigrantes, que se instalaron en el área conurbada de la Ciudad de México. Por ejemplo, en el Valle de México, tuvieron un crecimiento poblacional exponencial, los municipios de Nezahualcoyotl, Tlanepantla y Ecatepec entre otros, que se constituyeron en los mayores proveedores de fuerza laboral de la industria.

De acuerdo con Pérez (2021), "Debido a la demanda de ocupación, pronto comenzó la venta de lotes. Las primeras ventas eran ilegales pero a bajos costos (llegando a pagar de 3 a 5 pesos por m2 en 1945) y parecían ser la opción más indicada para tener una vivienda propia." Los asentamientos, de las personas que llegaban de las distintas entidades federativas, como Michoacán, Oaxaca, Veracruz, Guerrero, Estado de México, Puebla, etcétera; formaron una amalgama multi-inter y transcultural muy diversa, que por la necesidad de vivienda, se ubicaron en la periferia, en "ciudades dormitorio", que se fundaron sin los servicios básicos de agua, luz ni drenaje.

\footnotetext{
"Sobre este terreno falto de urbanidad, en la década de 1940, comenzaron a establecerse los primeros habitantes. Los recién llegados eran originarios de varias zonas rurales de provincia quienes arribaban en busca de las oportunidades laborales que les prometía la capital del país." (Pérez, 2021).
} 


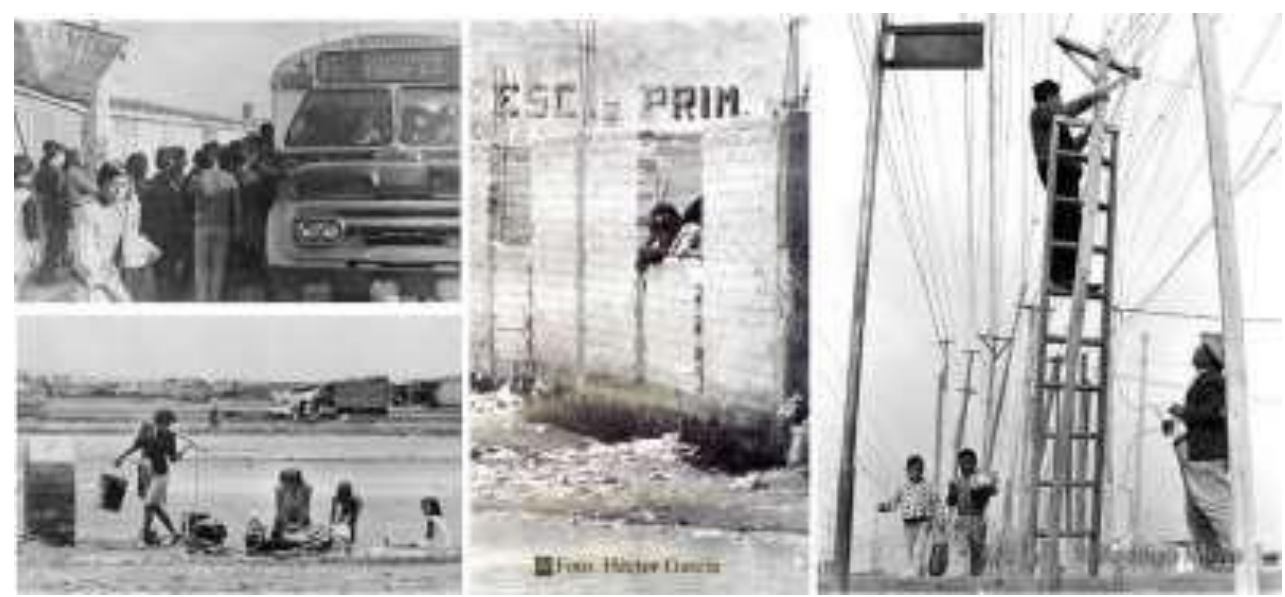

Figura 6. Migración y asentamiento en la periferia del Valle de México. Elaboración propiacon imágenes de Pérez y García (2021)

Los centros educativos para los hijos, también se crearon de manera informal con la colaboración de los colonos, con muchas carencias de infraestructura física y de personal docente, situación que con los años, con el esfuerzo de esta comunidad multicultural, se fue atendiendo.

\section{Periodo neoliberal y de exclusión}

A principios de los años 80 , a nivel mundial inició un cambio de modelo económico, promovido, nuevamente, desde los Estados Unidos e Inglaterra, encabezados y por Ronald Reagan y Margaret Thatcher, debido a que las empresas de los países industrializados sufrían problemas de sobreproducción y (en téminos de Marx) de "realización de mercancías". Requerían con urgencia la deslocalización de sus mercados, para ampliar sus economías a escala y prolongar el ciclo de vida de sus productos. Además, de reducir sus costos con la deslocalización de sus procesos productivosl

Si bien México, bajo el modelo de Sustitución de importaciones, alcanzó un crecimiento sin precedentes, éste no fue logrado de manera endógena, sino a costa de endeudamiento externo y déficit público.

Lomelí y Vázquez (2016), refieren que en 1981 comenzaron a declinar los precios del petróleo y a aumentar las tasas de interés en Estados Unidos. La negativa del gobierno mexicano a devaluar, con el consiguiente sobre-endeudamiento externo en las peores condiciones en términos de tasas y plazos, terminó por empeorar la situación y desencadenó el estallido de la crisis de la deuda en 1982, antecedente obligado para entender el cambio estructural.

A partir de 1983, México, por presiones del capital internacional, se integró al proceso globalizador, a través de un modelo neoliberal de apertura y desregulación de mercados: privatización, reducción del gasto público, y contención de salarios.

Oficialmente se afirmó que los objetivos de la apertura comercial y del cambio de modelo fueron:

a) Igual trato por parte del resto de los países y tener acceso al mercado mundial.

b) Reducción del costo y los trámites de comercio exterior, permitirá la obtención de insumos a menores precios.

c) Adquirir maquinaria y equipo avanzado a menores costos.

d) Recibir inversión extranjera directa y transferencias de tecnología y generación de más empleos.

e) La competencia internacional obligaría a las empresas a ser competitivas

A partir de 1983, México encaró el proceso globalizador, a través de un modelo de apertura y desregulación de mercados: privatización, reducción del gasto público, y contención de salarios, lo cual ha generado:

- Importación excesiva de bienes y servicios.

- Saldo negativo de la balanza comercial

- Dependencia de divisas del exterior.

- Desindustrialización del país

- Desempleo

- Informalidad.

El sistema capitalista y particularmente el modelo neoliberal, que esta sustentado en el individualismo, la competencia y la generación de riqueza, es por naturaleza un sistema que genera pobreza y exclusión, como 
fenómenos emergentes sistémicos. No es casual ni es producto del infortunio de los países pobres.

Es un sistema teleológico, que esta diseñado de manera compleja, para que ocurra lo que, de acuerdo a los diseñadores, debe ocurrir y está ocurriendo, arroja determinados resultados, que son el enriquecimiento de una minoría a costa del empobrecimiento y la marginación de la gran mayoría (Cruz,2021).

En la figura No. 7 podemos observar la estructura productiva cartografiada, de la misma manera con el software de redes neuronales Walrus; se diferencia de la anterior debido a que en ésta se le agregaron las "unidades productivas" que se generaron con el modelo neoliberal. Estos mini-micro negocios, son los empleos informales a los que tuvo que recurrir la población, al ser expulsados de la estructura productiva, como consecuencia del rompimiento de cadenas productivas y el consecuente desempleo.

La Encuesta Nacional de Ocupación y Empleo del Inegi (Instituto Nacional de Estadística y Geografía) reporta que el $57 \%$ de la población vive de activiudades informales.

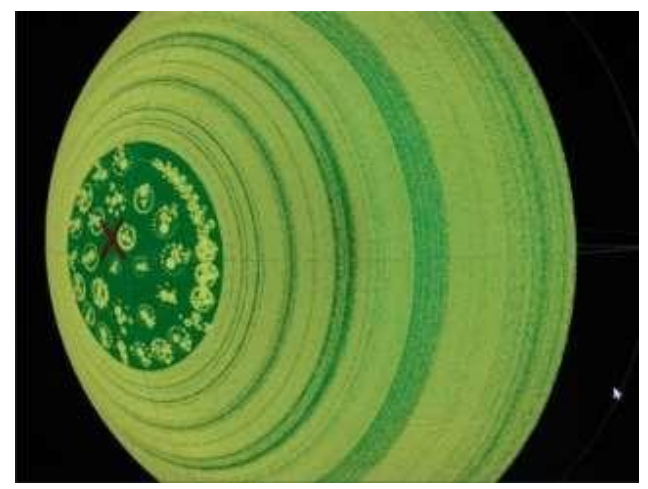

Figura 7. Expulsados de la estructura procuctiva formal. Elaboraciónpropia con información de la Secretaría de Economía (Cruz, 2011).

\section{Diversidad de los grupos sociales y el multiculturalismo de los estudiantes en las zonas urbanas}

En la Red de Libre Escala pudimos observar, que en torno a la estructura productiva hay una gran cantidad de excluidos del sistema, personas que laboran en la informalidad y que se suman a las zonas periféricas y marginadas de las ciudades, ahora poblando los cerros y las zonas más riesgosas de la orografía de las metrópolis.

Aquí están la mayoría de nuestros estudiantes de las áreas urbanas.
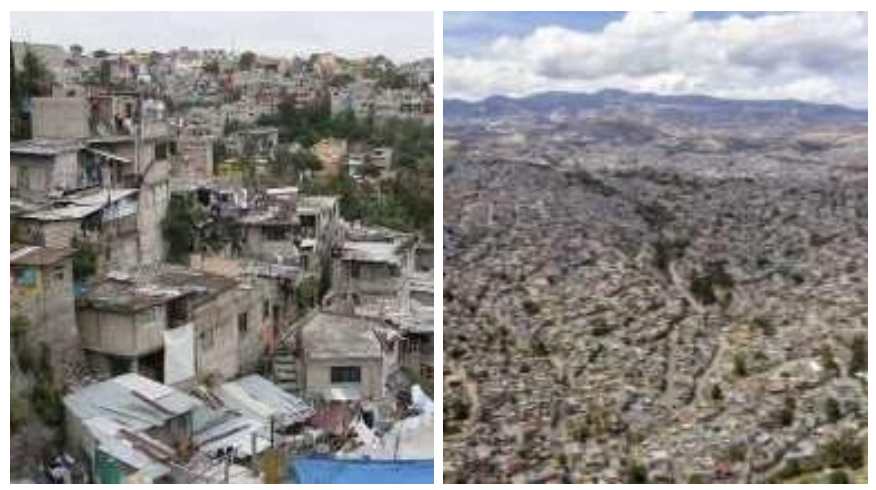

Figura 8. Expulsados de la estructura procuctiva formal. Imágenes deinternet

Lomnitz (2006) indica que los marginados son como los cangrejos: se alimentan de sus sobras y viven en los intersticios de la ciudad, física y económicamente hablando.

1. Cuando más se formaliza y se regula un sistema social y no satisface las necesidades de la sociedad, generalmente se crean mecanismos informales que escapan al control del sistema.

2. Redes de subsistencia, colaboración y resistencia.

3. Los modos informales de intercambio crecen en los intersticios del sistema formal.

4. Las transacciones informales obedecen a una lógica que muchas veces choca con la racionalidad económica, la ideología formal del Estado.

\section{El multiculturalismo de los estudiantes pertenecientes a grupos indígenas}

Otro grupo social, por demás marginado, es el que habita en las zonas rurales de México, grupos indígenas que poseen una gran diversidad étnica y riqueza cultural en México. Aun cuando no se tiene un registro preciso, podemos referir las siguientes cifras. En México existen:

- 70 pueblos indígenas

- Están integrados por 15 millones de personas

- Estos grupos hablan más de 95 lenguas.

- Son los pobres entre los pobres.

El Consejo Nacional de Evaluación de la Política de Desarrollo Social Coneval (2019), organismo que mide la pobreza en México y evalúa programas y políticas sociales del Gobierno Federal, publicó siguiente gráfico, del que podemos destacar que la población indígena y la población hablante de lenguas indígenas, son quienes más tienen rezago educativo (SIC), carencia de acceso a la seguridad social, carencia de espacios y de servi- 
cios en las viviendas y carencia de satisfactores alimenticios.

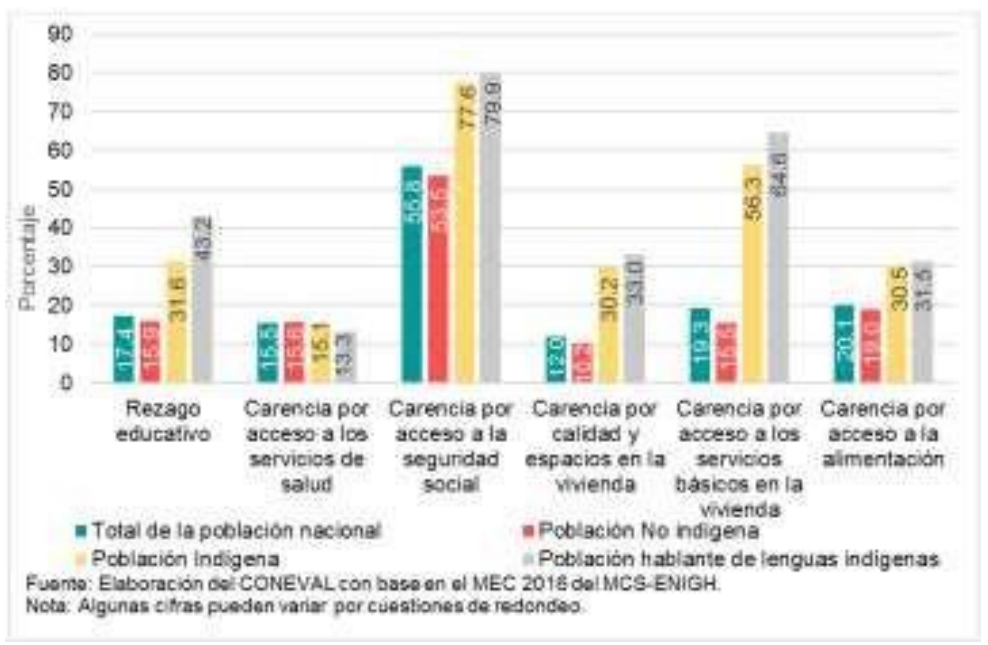

Figura 9. Grupos sociales con rezagos sociales. (Coneval, 2019).

Estos 70 pueblos y 15 millones de indígenas se encuentran, principalmente, en los estados de Michoacán, Guerrero, Oaxaca, Chiapas. Casualmente, las entidades donde los maestros se han opuesto de manera determinante a las reformas educativas promovidas por la OCDE.

\section{Caracterización de la educación como sistema complejo}

Cada vez más investigadores en el mundo estudian los Sistemas Complejos, cuyas características son:

- Estructura con límites difíciles de definir, abierta al medio ambiente con intercambio de materia, energía e información.

- Gran número de subunidades estructurados en forma de red.
- Efectos no proporcionales.

- Se da la autoorganización, derivada de conductas individuales.

- El desequilibrio es una condición para evolucionar.

- Se estructuran en forma de red y asumen diversas topologías.

En la siguiente figura se presenta una manera de cartografiar este sistema complejo, muy a la manera en que lo hacen los ingenieros, para graficar sistemas: Entradas, una caja de transformación, con los componentes o subsistemas que forman parte del sistema; las salidas, que en teorías son resultado de las entradas y el proceso e interacción de los subsistemas. Además, se muestran algunos fenómenos que afectan al sistema en estudio, en este caso, el sistema educativo.

- Interacciones e interdependencia entre los componentes.
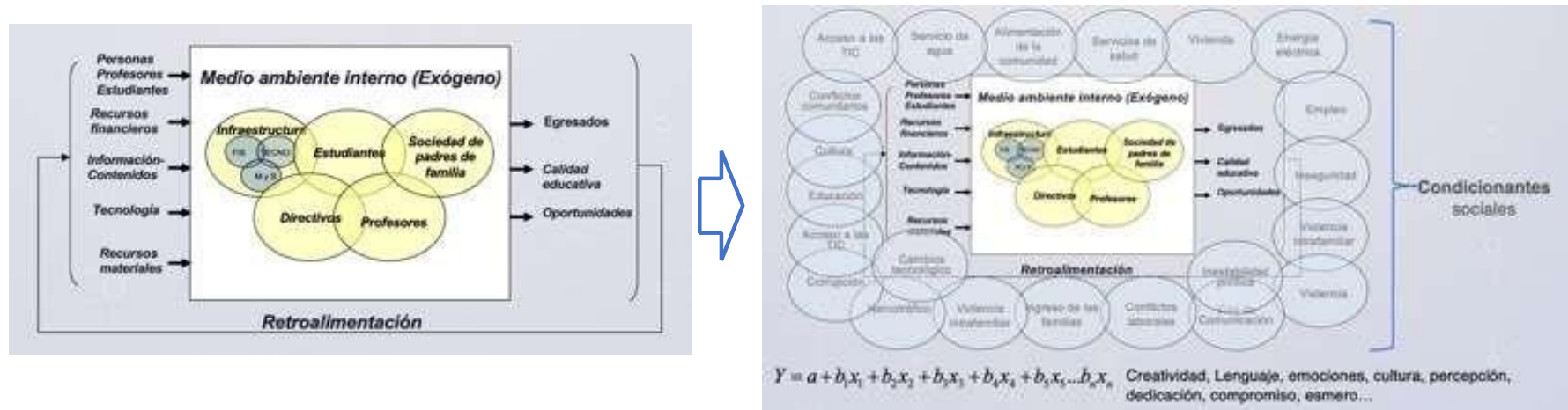

Figura 10. Sistema educativo. Fuente: Elaboración propia 
Sin embargo, aun cuando parece que es un sistema con una gran cantidad de componentes, interacciones y posibles resultados emergentes; la ilustración no muestra una serie de características que forman parte intrínseca de los grupos humanos y las personas; como lo son las emociones, la creatividad, el lenguaje, la percepción, la dedicación, el compromiso, la colaboración, el esmero, los esfuerzos, entre otros factores que son precisamente los que hacen funcionar la educación en los grupos marginados.

Otro de los atributos de los sistemas complejos es que, aún con las restricciones del sistema, afectaciones del entorno, escasez de recursos e infraestructura, siguen funcionando. Así es la educación en los grupos sociales marginados, que se diferencian del modelo de desarroIlo oficial, porque estas redes de resistencia, subsisten con base en los principios de la solidaridad y la colaboración.

\section{Las ciencias de la complejidad}

Podemos caracterizar a las ciencias de la complejidad como un conjunto de ciencias, disciplinas, teorías, enfoques, lenguajes y métodos para el estudio de fenómenos que no es posible abordar con las categorías propias de la ciencia normal.

Existen una gran cantidad de teorías, corrientes y enfoques de autores de diferentes latitudes del mundo, que con su obra han contribuido al desarrollo del Pensamiento Complejo las Ciencias de la Complejidad.

Este mapa de Castellani se caracteriza porque muestra el trabajo de las ciencias de la complejidad que se trabajan en los países desarrollados. Casi no hay latinoamericanos, con excepción de Varela y Maturana.

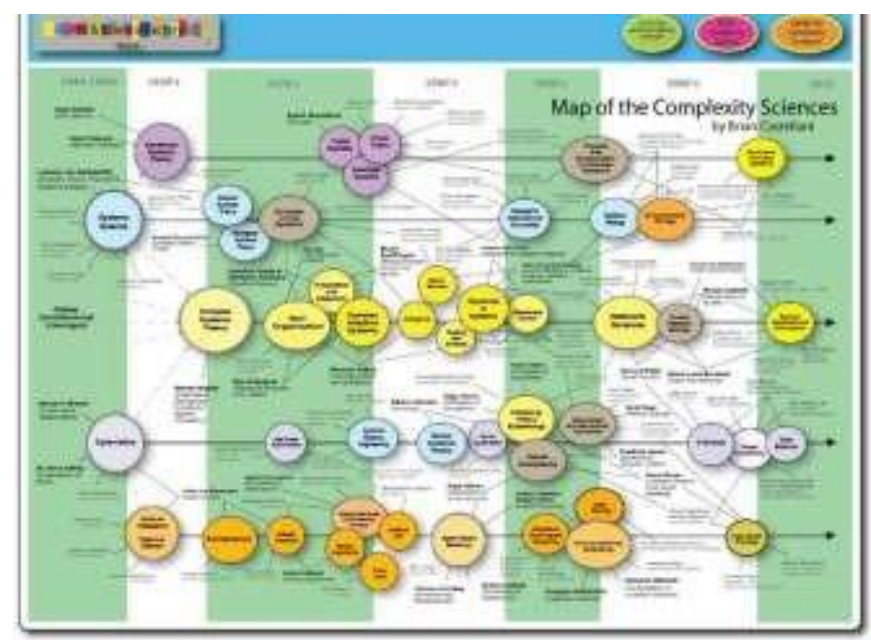

Figura 11. Mapa de las Ciencias de la Complejidad. (Castellani,2018).
De la misma manera que el sistema neoliberal evalúa y excluye a grupos sociales o individuos, la ciencia occidental; Castellani, ha dejado fuera de este mapa a muchos de los mejores complejólogos de primera generación en América Latina, sin tratar de ser exhaustivo citaré los siguientes: Carlos Eduardo Maldonado, Pedro Sotolongo Codina, Sandra Massoni, Rafael Pérez-Taylor, Deicy Alvarado, Mayra Espina, Raimundo Franco, Denise Najmanovich, Leonardo Rodríguez, Teresa Salinas, Pedro Luis Castellanos, etcétera.

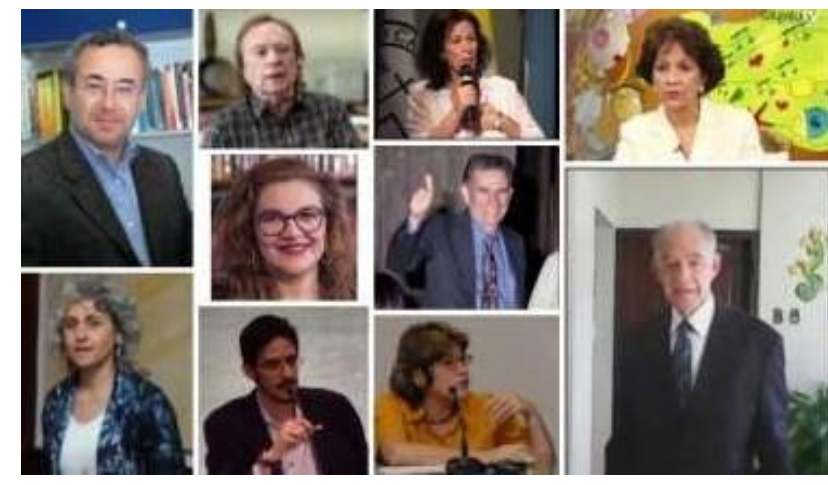

Figura 12. Complejólogos de primera generación en América Latina. Elaboración propia.

Desde hace más de 10 años, de manera autoorganizada existe una red autoorganizada de comunicación, colaboración interacción entre los grupos de complejidad de América Latina, integrada por complejólogos de distintos países como: Cuba, Colombia, Argentina, Perú, Bolivia, República Dominicana y México. Redes que son el producto de muchos años de trabajo de científicos con una visión contextual de las Ciencias de la Complejidad y las Ciencias Sociales en sus más diversas vertientes, entre las que se encuentra el campo de la educación.

Las Ciencias de la Complejidad ya cuentan un marco categorial y herramientas, en evolución, con los que se pueden abordar temas de diferente índole: social, medio ambiental, tecnológico, organizacional, médico, incluso en tema que nos ocupa, el educativo.

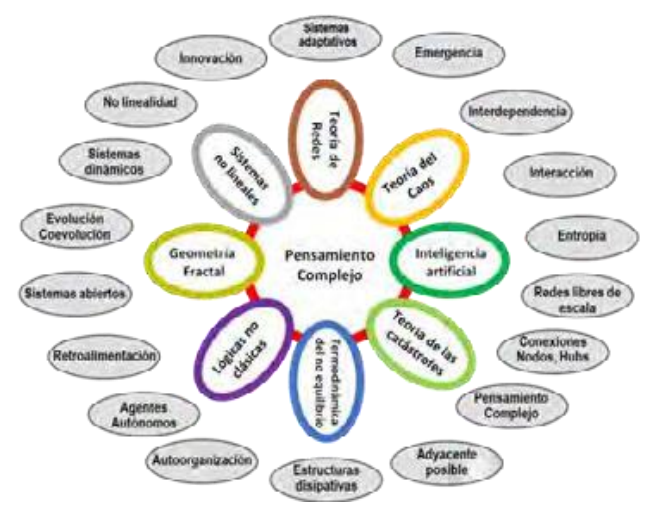

Figura 13. Marco categorial de las Ciencias de la Complejidad. Elabo-ración propia. 
Cabe señalar, que los Sistemas Sociales como el sistema educativo, no son sistemas determinísticos, solo por sus factores causales de entrada/salida. Como sistema teleológico construido por personas, depende de pre-condiciones de intencionalidad.

La educación es un fenómeno agregado, emergente que surge por la interacción que se da dentro del sistema y por causas del entorno. Es producto del trabajo conjunto de las autoridades educativas, profesores, familias, comunidad, entre otras. No obstante, el trabajo de la comunidad, del maestro y los estudiantes es fundamental.

\section{Modelos y prácticas educativas}

Hay una diversidad de modelos educativos o enfoques pedagógicos orientados a procesos de enseñanza-aprendizaje, incluyen técnicas para enseñar y dar clases, están estructurados con base a tres premisas fundamentales: que es el enfoque. ¿Qué es enseñar?, la metodología. ¿Cómo enseñar? y la a evaluación. Estos modelos se acompañan de un ideal de vida y de un proyecto de sociedad.

Estos modelos educativos poseen herramientas y los profesores, por muy puristas que seamos, en la práctica, aplicamos varias de ellas, de acuerdo con las circunstancias.

\begin{tabular}{|c|}
\hline $\begin{array}{l}\text { Siglo } \\
\text { XVII }\end{array}$ \\
\hline Tradicional \\
\hline $\begin{array}{l}\text { Meta: } \\
\text { Formación del carácter de los } \\
\text { estudiantes, moldeándolo a través } \\
\text { de la voluntad, el rigor y la } \\
\text { disciplina hacia el ideal del } \\
\text { humanismo ético. }\end{array}$ \\
\hline $\begin{array}{l}\text { Desarrollo: } \\
\text { Comprende el desarrollo de las } \\
\text { cualidades innatas a través de la } \\
\text { disciplina. }\end{array}$ \\
\hline $\begin{array}{l}\text { Contenidos: } \\
\text { Disciplinas clásicas y facultades del } \\
\text { alma }\end{array}$ \\
\hline $\begin{array}{l}\text { Relación maestro-alumno: } \\
\text { Vertical, el maestro es la autoridad }\end{array}$ \\
\hline $\begin{array}{l}\text { Método: } \\
\text { Academicista, verbalista, } \\
\text { transmisionista, desarrollado bajo } \\
\text { un régimen de disciplinas } \\
\text { en el que los alumnos son los } \\
\text { receptores y aprenden a través de la } \\
\text { imitación, el buen ejemplo y la } \\
\text { repetición, cuyp patrón } \\
\text { principal es el maestro. }\end{array}$ \\
\hline $\begin{array}{l}\text { Representantes: } \\
\text { Juan Comenio } \\
\text { Johann Herbart }\end{array}$ \\
\hline
\end{tabular}

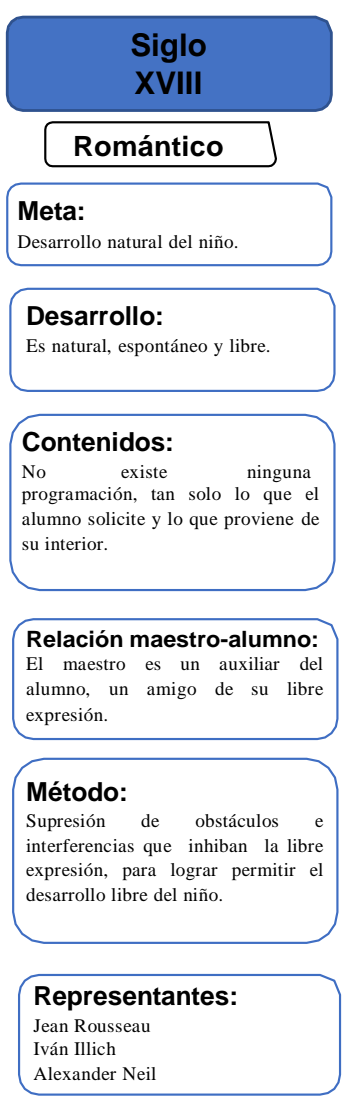

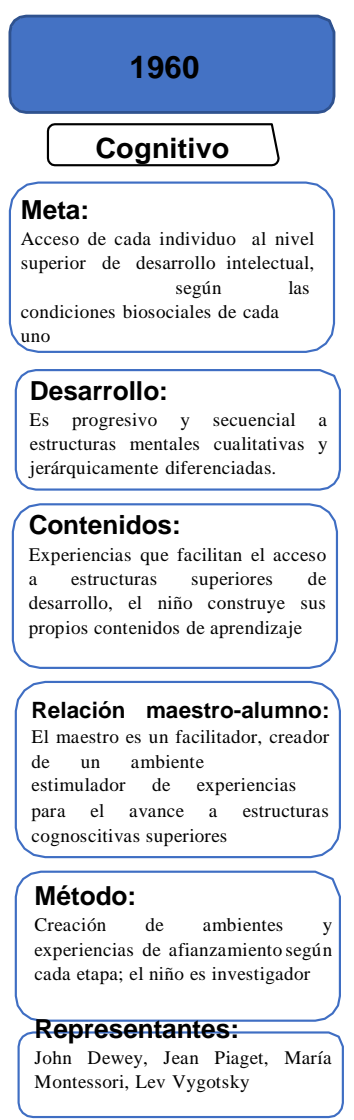

Figura 14. Modelos educativos. Elaboración propia.

Dichos modelos a lo largo de la historia se han tratado de imponer a comunidades con el propósito de afianzar un orden social, político y cultural, conforme a las necesidades de determinado modelo de sociedad. Se imparten conocimientos con metodologías propias, que posteriormente son evaluadas.

Sin embargo, el intento de búsqueda de la calidad educativa termina por homogeneizar los procesos de enseñanza. Estos se tornan rutinarios, mecánicos, y como contrapartida, priorizan los resultados (alto rendimiento escolar, demostrado en números) por encima de los procesos. Por ejemplo, las evaluaciones estandarizadas PISA no evalúan procesos, sino resultados obtenidos por los estudiantes en áreas del conocimiento básico (ciencias, matemáticas y lectura). Sin embargo, dejan de lado otras áreas y aspectos de la educación igual de importantes: arte, música, factores relacionados con las actitudes y valores (Santos, 2016). 


\section{0. ¿Quién evalúa la educación?}

La OCDE (Organización para la Cooperación y el Desarrollo Económicos) es una institución creada por los países más poderosos del mundo para establecer las condiciones apropiadas para la expansión y el desarrollo económico de sus países miembros; establece estándares internacionales en diferentes campos, entre los cuales se encuentra el de la educación.

La OCDE impone las metodologías de evaluación que privilegian la Educación Bancaria que dilucidó Paulo Freyre, la medición estadística, los indicadores, además de modelos de educación orientada a los resultados, para satisfacer la demanda del mercado que reproduce la fuerza de trabajo y las condiciones de acumulación y desacumulación en el mundo.

Se ha difundido una narrativa sesgada en la que a los países pobres se les convence de que siguen siendo un grupo social de salvajes a los que hay la necesidad de modernizarlos conforme al modelo civilizatorio que conviene a los países industrializados.

Se afirma de manera categórica que la educación que se imparte en las comunidades es mala, pero cabe preguntar ¿mala para quién?

¿Por qué nuestros estudiantes no aprueban la prueba PISA?

¿Lo que es importante para la prueba PISA es para los niños y jóvenes?

¿Es una buena educación cumplir con un currículo?

¿Educación es entregar información? ¿Qué información? ¿Educación bancaria?

¿Quién y por qué se toman el derecho de decirnos cómo educar?

Imponer un modelo o modelos

¿Por qué estandarizar lo que es por naturaleza diverso?

No obstante que al neoliberalismo lo presentan como un proceso lineal e irreversible; la globalización no es tan global como parece, en virtud de que el ejercicio del poder genera cuotas de contrapoder. Solo a manera de ejemplo la resistencia de la Asamblea Popular de los Pueblos de Oaxaca (300 pueblos), que desde hace décadas ha defendido su derecho a la autodeterminación en materia social política y educativa en las que subyace su forma de gobierno, en donde las decisiones más importantes se toman a través del consenso y el bienestar común.
Al respecto, ¿Qué pueden aportar las Ciencias de la Complejidad y el pensamiento complejo a estas comunidades multiculturales, rurales y urbanas? Hemos sustentado que la educación debe ser estudiada de manera multidimensional, desde su contexto y que debe darse la autoorganización, la emergencia, que debe ser un proceso que emerja en forma sistémica desde lo micro, desde la vida cotidiana, con base en el trabajo colaborativo, el humanismo y el bienestar de las comunidades.

Conviene citar a Humberto Maturana (2014) quien definió la educación como: "Transformar en la convivencia". "Nos producimos a nosotros mismos en un nicho ecológico que lo hace posible".

Las comunidades, escuelas, maestros, estudiantes, familias, se autoorganizan, en la búsqueda de usar en forma eficiente los recursos, reacomodan su estructura, su organización, prácticas y acciones. A través de la colaboración hacen que funcione, lo que no debería funcionar.

Por su parte, Stuart Kauffman habló de la autocatálisis colectiva, en donde yo catalizo tu formación, tú catalizas mi formación y muchos otros catalizan la formación de otros tantos, y por tanto son colectivamente capaces de autocatalizarse. Más o menos, yo te construyo a partir de piezas tuyas, y tú a mí, a partir de piezas sueltas mías. En consecuencia, nadie se construye o reproduce a sí mismo mediante sí mismo, sino que entre nosotros somos colectivamente autocatalíticos.

De lo anterior, se deduce que, desde fuera, como teóricos estamos incapacitados para formarlos con partes nuestras, si no convivimos con ellos si no provocamos la autocatálisis colectiva con estos grupos.

Como conclusión, podríamos mencionar que ni el gobierno, ni la academia, debemos ceder a la tentación encontrar un modelo educativo para los grupos o comunidades multiculturales, en una relación de autoridad cognitiva y de sometimiento, aunque le llamemos a nuestras propuestas multiculturales, incluyentes, orientado a la diversidad, etcétera. En este, como en todos los casos, debe prevalecer el respeto a la autodeterminación de los pueblos para que, desde lo micro, lo cotidiano, lo contextual, las comunidades decidan con toda libertad, por ellos mismos, su educación. No necesariamente debe haber un modelo, por la complejidad de estos grupos sociales pueden existir tantos modelos como pensamientos situados pueda haber.

Los educadores tienen una cosmovisión distinta, que les ha procurado un devenir complejo y que difícilmente 
podremos entender desde la academia, desde los centros de investigación, los cubículos.

- Así como en el artista popular trabaja con los elementos de su entorno, los maestros en sus comunidades llevan a cabo el proceso educativo con los recursos que les proporciona su imaginación, su creatividad su pensamiento y sus aspiraciones.

- Como herramientas, disponen de colores, texturas, sabores, situaciones, emociones y experiencias que les permiten relacionarse con sus estudiantes y con las familias de la comunidad.

- El maestro aborda la complejidad de su grupo, con trabajo, mucho trabajo, dedicación, empeño, esmero, compromiso.

- Con su estilo docente, con base en sus experiencias y todo el bagaje del que le dota su propia complejidad.

- Las herramientas las toma de los modelos educativos, las adapta e implementa de acuerdo con su circunstancia.

- Promoviendo el respeto, la autonomía, la dignidad y la reflexión

\section{Referencias}

Caponi, Sandra (2013). "Quetelet, El Hombre Medio Y El Saber Médico". História, Ciências, Saúde-Manguinhos 20 (3). Fundação Oswaldo Cruz. [En línea]. Disponible en:

Castellani, Brian (2018) Mapa de las Ciencias de la Complejidad. [En línea]. Disponible en: https://www.art-sciencefactory. com/complexity-map_feb09.html

Coneval (2018). Medición de la pobreza 2008-2018. [En línea]. Disponible en: https://www.coneval.org.mx/Medicion/ PublishingImages/Pobreza_2018/Serie_2008-2018.jpg
Cruz, E. (2011). Estudio, Medición y Evaluación de la Competitividad, un Enfoque de la Teoría de los Sistemas Complejos. Tesis Doctoral: UNAM.

Cruz, Eligio (2021). Las redes multidimensionales e intertemporales de sistema de poder capitalista y la revolución del pensamiento en américa latina. Revista Conjeturas. No. 24, Año 9, enero-abril 2021. Universidad de El Salvador. [En línea]. Disponible en: https://ciudaddigna. org/2019/12/desigualdad-en-mexico-no-es-natural/

Keynes, John (1936). Teoría General del Empleo, el Interés y el Dinero. [En línea]. Disponible en: http://biblio.econ.uba.ar/ opac-tmpl/bootstrap/Textocompleto/Teor\%C3\%ADa\%20 general\%20de\%20la\%20ocupaci\%C3\%B3n, \%20el\%20 inter\%C3\%A9s\%20y\%20el\%20dinero\%20-\%20\%20 John\%20Maynard\%20Keynes.pdf

Lomelí, Leonardo y Vázquez, Laura (2016). Cambio estructural y migración. Revista Economía, 2016. Universidad Nacional Autónoma de México. [En línea]. Disponible en: http://revistaeconomia.unam.mx/index.php/ecu/article/ view/26/405

Lomnitz, Larissa (2006). Cómo Sobreviven los Marginados. Siglo Veintiuno Editores. México.

Kauffman, Stuart (2007). Entrevista "Nuestro aparato sensorial no es la única colección posible de modalidades sensoriales útiles". [En línea]. Disponible en: http://www.percepnet. com/perc04_07.htm

Maturana, Humberto (2014). Entrevista "Todo Sistema Racional se funda desde la Emoción". [En línea]. Disponible en: https://www.youtube.com/watch?v=NIVfWd5yYLs

Pérez Kenia (2021). México Desconocido. [En línea]. Disponible en:

https://www.mexicodesconocido.com.mx/historia-de-ciudadneza.html

SANTOS, M. (2016), diciembre 10. PISA o la cesta de piedras. En La opinión de Málaga. [En línea]. Disponible en: https:// goo.gl/ss]c9h 